\title{
Research Progress of Dunhuang Ancient Prescriptions
}

\author{
Bolin Yang, Xiping Liu \\ Gansu University of Traditional Chinese Medicine, Lanzhou, China \\ Email: wangchengtianfu@163.com
}

Received 6 February 2016; accepted 21 February 2016; published 29 February 2016

Copyright (C) 2016 by authors and OALib.

This work is licensed under the Creative Commons Attribution International License (CC BY).

http://creativecommons.org/licenses/by/4.0/

(c) (i) Open Access

\begin{abstract}
Dunhuang medical examination paper contains about 1100 ancient prescriptions. From the ancient prescriptions of literature research, experimental study and clinical study summarized from three aspects, this article gets a conclusion: of Dunhuang ancient prescriptions dose research rarely, the formulas of TCM side cannot pass the secret lies in the dosage, so Dunhuang ancient prescriptions dose is worth of further clinical research.
\end{abstract}

\section{Keywords}

Dunhuang Medical Examination Paper, Traditional Chinese Medicine and Pharmacy, Dunhuang Ancient Prescriptions

Subject Areas: Internal Medicine

\section{1. 敦煌遗书中的古医方概况}

\section{1. 敦煌遗书中的中医药文献}

敦煌卷子显世之后, 应运而兴起一门新的学科—— “敦煌学” “ “敦煌学”之称是因地而命名的学 科群组合, 包括: 敦煌莫高窟和其它临近的石窟寺; 敦煌遗书; 其它(河西走廊有关的文化遗存和文物、 文献)。其中, 敦煌遗书是指前的人遗著和前人所藏之文书经籍, 它们多正背两面兼写, 具有数量大、时 间长、抄本多、范围广等特点。

敦煌中医药文献是敦煌学的一个重要学科, 在敦煌石窟艺术和敦煌遗书中占有重要地位, 从基础到 临床各科自成体系, 在大量的壁画、彩塑、图案、汉简、题记、书法及藏经洞大批遗书中都有相当数量 的描绘和记载。 
敦煌遗书中的中医药文献包括: 敦煌医理类著作、敦煌古藏医药类著作、敦煌针负类著作、敦煌诊 法类著作、敦煌本草类著作、敦煌医方类著作、敦煌遗书道医资料、敦煌遗书佛医资料、敦煌遗书医事 杂论、形象医学等内容[1]。

\section{2. 敦煌中医药文献中的古医方内容及其来源}

敦煌中医药文献中的医方类是指以临床医疗为主的专书。其内容大多为治疗各类病症的方书[2]。

敦煌医方类著作包括: 《杂症方书》、《王宗无忌单方》、《单药方》、《配方选药法》、《脚气、 疮病方书》、《杂疗病药方》、《头、目、产病方书》、《黑帝要略方》、《医方残片》、《疗胸痹心 痛医方残片》、《治病药名文书》、《简便医方方书》、《美容方书》、《求子方书》、《配伍组方法 要》、《服食养生方书》、《无名方书目录》、《妇科单药方书》、《疗服石医方》、 《服气休粮及妙 香丸子方》、《道家养生方》、《绝谷仙方》、《残辟仙方》、《道家合和金丹法》、《佛家医方》、

《佛家辟谷方》、《佛家香浴方》、《佛家养生方》、《佛家语喻医方》、《佛家疗病催产方》、《佛 家神妙补心方》、《辅行诀脏腑用药法要》、《吐蕃医疗术》、《张仲景五脏论》等。

纵观敦煌遗书医方类著作, 不难看出有些方子虽然见于前代医学传世方书, 而其中大多数是隋唐五 代的医学家的经验医方, 是以手抄本留给后人的[1]。

\section{2. 敦煌古医方文献研究}

\section{1. 敦煌佛教医方}

敦煌佛教医方是敦煌医学的重要组成部分, 是佛教医书与中医学紧密结合的部分。敦煌佛教医方根 据佛教义理组成医方, 将佛教咒语与药物结合并巧妙借助天王推广医方, 丰富了中医学。如敦煌卷子 P.3930 原文中有 “治女人难产方: 上吞㿝荚子七枚, 验。又方: 有咒法, “南无干施婆, 天使我广说此 咒偈, 邪唎邪唎邪婆惺呈他邪婆怛他莎诃, ”。上此咒于华皮上抄之, 净嗽口, 含净水, 烧香佛前, 一 气抄之, 但觉欲产时。此处佛教咒语被用来治疗妇人难产[2]。

\section{2. 《亡名氏脉经第二种》、《张仲景五脏论》与《疗胸痹心痛医方残片》(S•079)}

《脉经》这部重要的脉学专著, 在阐述脉象的同时, 涉及到了许多方剂, 却无主治和组成, 大多为 仲景方, 可资考证, 但有许多方剂早已佚失, 无从考证。探查敦煌遗书 P·3477、P·3665, 特别是《亡名 氏脉经第二种》 (P-3287)中的内容与《脉经》十分接近, 据考证可能传抄于唐武则天时期, 未经宋臣的校 勘整理, 较多的保留了原书概貌。其中的 7 首方剂对考证《脉经》佚方提供了重要线索, 弥足珍贵[3]。

主要为桂枝汤、葛根汤、摩风膏、㫿麦汤、滑石散、平胃丸和前胡汤, 这些方剂其主治、组成、用 法详明, 组方严谨。有些方名虽亦见于《伤寒杂病论》(桂枝汤)或《千金方》(滑石散、平胃丸、前胡汤), 但其组成用法、组方思路截然不同, 或许这就是王叔和《脉经》的原方, 不但具有重要的史料价值, 更 具有一定的临床实用价值, 值得进一步研究[4]。

敦煌医学卷子《张仲景五脏论》成书于隋唐时期, 是一部托名之作, 为民间医生或文人兼医者所作。 它将文字深奥难懂的古医籍通俗化为一种普及性的中医读物。写本所载五首方剂无具体药物组成, 只有 方名和功效: 八味肾气丸(补六极而差五劳); 四色神丹(荡千疴而除万病); 槟榔汤(下虫除气); 玉壸丸(破 积癖消痃); 黄龙汤(出其则内, 时气病者能除) [5]。

据考证《疗胸痹心痛医方残片》(S·079)所载 “栝楼汤” 与元·邓珍《新编金贵方论》、唐·孙思䢬《千 金要方》、唐·王奉《外台秘要》有相似之处, 而这几本书收录了汉·张仲景《伤寒杂病论》中的部分原文、 
方剂。因此, 敦煌古《疗胸痹心痛医方残片》(S·079)与汉·张仲景《伤寒杂病论》有洮源关系[6]。

\section{3.《辅行诀脏腑用药法要》}

《辅行诀脏腑用药法要》 (以下简称《法要》) 是一部保存较完整的敦煌医学卷子, 其内容丰富, 涉及 医理、医方, 临床用之多验。

《法要》包括: 55 首医方, 治病的范围非常广泛, 包括五脏的虚实病变、误治病变、外感时气病变、 急性病变等[7]。

《汤液经图》出资敦煌遗卷中梁·陶弘景所撰之《辅行诀脏腑用药法要》, 该图据撰者陶弘景云: “此 图乃《汤液经法》尽要之妙, 学者能谙于此, 医道毕矣”。

本图下方有一句释言: “阴退为泻, 其数六, 水数也; 阳进为补, 其数七, 火数也”。在《伤寒杂 病论》中也有类似说法: “发于阳者七日愈, 发于阴者六日愈, 以阳数七, 阴数六故也”。这种阳数七, 阴数六的观念在《辅行诀》五脏病诸方及《汤液经图》中均有所体现: 《辅行诀》中五脏病症大补泻诸 方, 除大补心汤药味为 6 味, 其余肝、心包、脾、肺、肾四脏一腑的大补汤药味均为 7 味, 大泻汤药味 则均为 6 味。而大补心汤证的症状也明显属于实证, 所施实乃泻实之法。这种药味的数量规定或许是对 “阴退为江, 其数六, 水数也; 阳进为补, 其数七, 火数也” 的直观体现, 姑且不论其临床意义, 但至 少从一个角度体现了阴阳学说在当时组方行为中的深刻影响[8]。

\section{4. 专科方剂}

关于妇科的方剂敦煌遗书也有记载, 如: 现藏于英国伦敦博物馆标号为 S. $6177_{2}$ 的 《妇科单药方书》 其内容主要论述妇产科疾病的单味药治疗经验; 《求子方书》、《杂证方书第一种》、《杂证方书第三 种》、《杂证方书第八种》、《单药方》、《头、目、产病方书》、《杂疗病药方》等方书中也有一些 关于妇科的方剂[9]。

敦煌遗书中有一部专门治疗男性病的专著, 即《黑帝要略方》。此书现藏于法国巴黎国立图书馆, 编号为 P.2565。其创作年代似为唐末、五代之际写本。由于大多药方均有缺损, 故其数不详。可辨诸病 有阳瘘、房损、阴疮、男子卵肿等数种。故认为是一篇专门记载男性病的著作[10]。

\section{5. 敦煌汉简}

《敦煌汉简》共收录简牍 2428 枚, 公元 1906-1979 年之间发掘于敦煌周边汉代城障烽隧遗址, 简牍 的纪年上限最早为汉宣帝本始 3 年, 最晚为王莽新始建国天凤 6 年。因此这批汉简应属西汉时期戍边队 伍的简读。其中医药简 100 余枚, 内容涉及病症、药物、方剂、治法、针炎等。

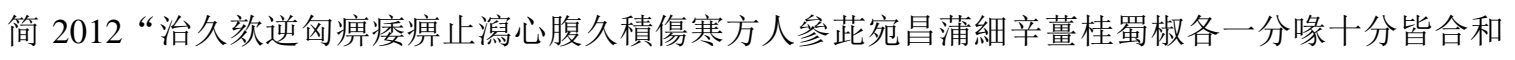
以”。“逆” 当 “喘”、当 “呕” 解; “痹” 当 “不通”, 引申为 “憋满”; “瘘” 当 “无力” ; “心 腹久积” 当心下胃脘部久有积邪, 方中药物为: 人参、紫苑、菖蒲、细辛、姜、桂、蜀椒, 多为温热之 品而无大黄、芒硝等荡涤之药。 “以方测证” 此处之 “心腹久积” 应为 “积水” 而非 “饮食积滞” 。《伤 寒论》中小青龙汤主治 “外寒内饮” 之证, 说明 “伤寒方” 已有了小青龙汤的倠型, 而《伤寒论》亦是 在 “伤寒方” 的影响下诞生的[11]。

\section{6. “酒”、“醋”在敦煌古医方中的应用}

酒, 可温通经脉、活血化瘀。在敦煌遗书现存的药方中, 用的较多的为: 清酒、灰酒、白酒、蜜酒、 
牛膝酒等, 酒入药的方式可分为 “和酒服之、酒浸、以酒煎药、捣末, 白酒和涂、洗” 等。药用酒量的 大小与诸多因素有关, 如使用方式不同、药性不同、饮酒者自身的酒力等。此外, 敦煌遗书对汤酒中的 药有限制, 如: 龙 503 号文书载: “凡汤酒膏中用诸石, 皆细捣之如粟米。” 即对于要制成亳药的石质 药物, 需要捣成碎末。其实, 不仅制作膏药如此, 在浸泡时, 对较为坚硬的药物, 也需捣成或刮成末状, 如虎骨、鹿角、杨树枝等, 其目的在于使其更易浸透, 药性能更充分地发挥; 敦煌遗书对制作清药酒有 限制, 药酒制作时限可根据季节、药性来确定, 使其浓烈适宜; 敦煌遗书对膏药制作中的用酒有限定: 制取膏药可用苦酒, 但限定其量不必太大, 要密封不泄气, 且有明确的时间限定[12]。

敦煌遗书古医方中有 18 首处方用米醋, 其中治疗内科、妇科疾病的处方有 12 首, 治疗外科疾病外 用者有 6 首。如: 敦煌遗书《杂证方书》 $\left(\mathrm{P} \cdot 2662_{2}\right)$ : “治产后血闷方, 好墨, 醋研, 服一合。” 墨, 松 之烟也, 气味辛温无毒。主治止血, 生肌肤, 合金疮, 治后血晕(血闷), 崩中卒下血, 用醋磨服之, 达到 补虚社瘀、生化止血、醒脑开空之作用; 敦煌遗书《治病药名文书》 $\left(\mathrm{S} \cdot 1467_{2}\right)$ : “染发令黑方: 醋浆水 者大豆以涂染渍之, 黑如漆。”[13]

\section{7. 西域医家方剂}

敦煌古医方《杂症方书第五种》(P·2662 $)$ 所载 “紫苏煎” 是治疗肺病上气咳嗽或吐脓血方, 临床应 用治疗内外妇儿等科疾病疗效显著。

原文记载为: 紫苏煎治肺病上气咳嗽或吐脓血方紫苏(一升, 酒研取汁)款冬花桑根白皮桔梗(各三分) 甘草(四分)诃勒皮(二分)杏仁(五分, 去皮尖, 㥿)石蜜(五两)猫牛酥(一升)贝母通草(各三分)右件药捣篎为 末，和酥蜜等微火上煎一两沸，置器中，以生绢袋子及绵囊口弹丸大，含之口咽汁。

经与传世文献《千金要方》、《千金翼方》、 《外台秘要方》等方书进行对比, 发现没有与敦煌紫 苏煎组成相同的医方, 从紫苏煎中的药物牦牛酥、诃勒皮等组成来看, 该方很有可能来源于西域的医家, 也有可能是中原医家经丝绸之路传入西域后经当地医家结合外来药物化裁而成, 这两种情况均反映了丝 绸之路医药文化中的中原医药文化与西域医药文化的密切交流[14]。

\section{3. 敦煌古医方实验研究}

有实验研究表明: 敦煌固本方能缓解负荷运动导致的胞浆内钙离子大量聚集, 提高 ATP 酶、己糖激 酶活性, 从而改善运动负荷造成的骨骼肌缺血、缺氧状况[15]; 具有清除自由基、抗氧化的功效, 同时对 力竭运动导致的小鼠外周血细胞 DNA 的损伤具有保护作用[16]; 敦煌固本方具有明显的抗疲劳作用[17]。

敦煌平胃丸组成源于敦煌遗书 P. 3287 卷子, 临床主要用于治疗慢性萎缩性胃炎及胃癌前病变。

\begin{tabular}{|c|c|c|}
\hline & 药物组成 & 主治 \\
\hline 平胃丸(P.3287) [18] & $\begin{array}{c}\text { 蜀大黄十分(去皮)、当归五分(生布拭)、 } \\
\text { 痋虫五分(去足, 㥿香用)、 } \\
\text { 防风五分(生布拭去土)、 } \\
\text { 蜀附子八角者三分(清酒渍半日, } \\
\text { 炮炘, 去皮及心称之)、干姜五分、 } \\
\text { 人参五分(拭去土)、葍本五分(去皮称)、 } \\
\text { 玄参五分(去土)、苦参五分(去皮)、 } \\
\text { 桔梗五分(去土) }[18]\end{array}$ & 心悬，饥不用食[18] \\
\hline 敦煌平胃丸[19] & $\begin{array}{l}\text { 大黄、当归、土鳖虫、防风、干姜、 } \\
\text { 人参、㮚本、玄参、苦参、桔梗[19] }\end{array}$ & 慢性萎缩性胃炎胃癌前病变[19] \\
\hline
\end{tabular}


如上表所示:

从药物组成来看: 敦煌平胃丸是平胃丸(P.3287)痋虫换为土鳖虫、去蜀附子而成。据陈秀园. 《神农 本草经读》记载: 附子, 气味辛、温, 有大毒。主风寒咳逆邪气, 温中, 金疮, 破痔坚、积聚、血瘕, 寒湿瘘壁, 拘挛, 膝痛, 不能行步。……即阳气不足, 寒气内生, 大汗、大泻、大喘、中风、卒倒等证, 亦必仗此大气大力之品, 方可挽回。此《本经》言外意也。现代研究表明敦煌平胃丸治疗慢性萎缩性胃 炎及胃癌前病变疗效显著。其机制可能与下调 Notch 信号通路中 Notch2 与 Jagged1 表达有关[19]。

敦煌石室大宝胶囊是从敦煌石窟遗书中化裁而成, 其组方原理根据明·薛己 “滋化源”和清·叶天士“甘 药培中，血肉填精” 的养生理论。其组成有熟地、黄芪、当归、获苓、大黄等药物[20]。

敦煌石室大宝胶囊可提高衰老模型动物脑组织单胺类神经递质的含量, 对善大脑功能有调节衰老大 鼠脑组织钙稳态有一定的作用[21] [22]。

\section{4. 敦煌古医方临床研究}

\section{1. 治法理论}

敦煌古医方有关于治疗 “臌胀” 的记载, 其治法主要为: 1)注重攻补兼施, 如牛黄丸(《杂证方书》 P.2565)中用人参、获苓益气健脾, 补虚扶正, 当归、芳药、川芎养血活血; 2)注重降泻肺气, 如蛊水遍

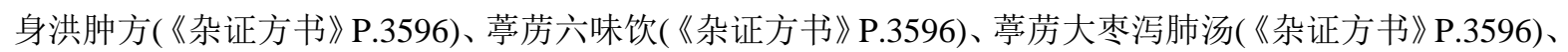
葶芳杏仁丸(《杂证方书》P.3596)等四方均用葶芳子。葶芳子苦寒降泄, 入肺、膀胱经, 泄肺气之雍滞, 善行膀胱之水。肺为水之上源, 肺气通则水道利。故用其开源导流、提壸揭盖; 3)注重食疗, 如服麻黄 汤(《脚气·㾏病方书》P.3201) “中间进少弹以助胃气” [23]。

\section{2. 制方思想}

在敦煌医学卷子 P.2662V、P·3378 中记载用诃梨勒组方治疗多种疾病: 1) 与槟榔合用, 理气治痢: 槟榔汤(P·2662V 第 10 行): “诃梨勒三颗、槟郎(榔)二枚, 末, 空腹服之” ; 2) 与桂姜草合, 重治风冷: 疗风热冷不调方(P·3378 第 4-5 行)甘草、干姜、桂心、诃梨勒, 以水一升, 煎取半升, 服之即差(痏)。“以 方测证” 此处的 “风冷热” 应偏重 “风冷” 证属脾肾阳虚, 临床可见畏寒, 肠鸣泄泻等症; 3) 寓三黄汤 中, 㾆风冷热: 疗风热冷不调方(P·3378 第 6-8 行)三黄汤方: 麻黄、黄芩、勺(药)药、葱白、鼓、防风、 黄芪、甘草、大黄、诃梨勒, 十二物, 以水一升半, 煮取一升, 服之即差(㽷)。 “以方测证” 此为表感风 寒里实、虚中夹实证。方中麻黄、葱白、防风解表, 豆豉、黄芩、大黄清江里热, 黄芪、甘草益气调中, 勺(苟)药、诃梨勒玫阴涩肠, 诸药合用, 散中有收, 攻中有补; 4) 合秦艽牛乳, 疗百种风病: 疗人一切 百种风病(P·3378 第 9 行): “秦芜一两、牛乳二升、煎取一升, 下诃梨勒, 服之痏” 唐. 《新修本草. 禽兽 部卷第十五》: “牛乳, 补虚贏, 止渴, 下气。”与诃梨勒、秦芜合用则补虚社风, 使社风而不伤正, “以方测证” , 本方所治风病乃寒湿所致; 5) 入桃柳枝汤, 疗老舅少力: 疗人老舅少力, 煎桃柳枝汤(P·3378 第 11-12 行)东南桃枝一握、东南柳枝一握、葱、豉、苟药、甘草、大黄、诃梨勒, 煎汤服之, 立差(㾘)。 “以方测证” 本方所值应为脾胃虚弱、热结营亏证; 6) 加牛酥紫草, 治上气咳嗽: 疗人上气咳嗽方(P·3378 第 13-14 行); 7) 入当归艾叶, 疗腹痛不止: 疗人腹皮痛不止方(P·3378 第 16 行)当归、艾、诃梨勒, 煎

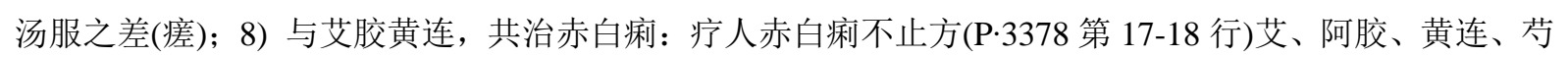
药、当归、桂心、椒、姜、诃梨勒, 以水二升, 煎取一升, 分二服, 服之即差(痏)。“以方测证” 本方主 治应为寒热错杂之赤白痢; 9) 诃毗阿摩罗, 醋煎治发落: 又疗发落(P-3378 第 24-26 行): 以诃梨勒二两 去子、毗黎(梨)勒二两去子、阿摩罗二两, 三物以醋、浆各二升, 煎滓, 洗头, 一日洗五度。空煎阿摩罗 
二两, 洗之亦差(痏); 10) 单味诃梨勒, 又可疗眼疮(P-3378 第 32-33 行): 又疗眼开不得, 有疮, 取诃黎 勒心, 冷水, 沛目中着, 立差(疘)。诃梨勒自东汉末年从西域传入中原后, 与中原药物组方配伍灵活运用, 治疗多种疾病, 这些药物至今仍有开发利用价值[24]。

王道坤教授运用敦煌平胃丸加减化裁治疗慢性萎缩性胃炎脾虚心悬、饥不用食有效率达 $98 \%$, 彻底 治愈率达 62\%。

敦煌平胃丸来自敦煌医学卷子《亡名氏脉经第二种》(P·3287) “平胃丸方。主心悬, 饥不用食。蜀大 黄(十分, 去皮)当归(五分, 马尾者, 生布拭)痋虫(五分, 去足, 獒香用)防风(五分, 生布拭取土)蜀附子八 角者(三分, 清酒渍半日, 炮坼, 去皮及心秤之)干姜(五分)人参(五分, 拭去土)藻本(五分, 去皮秤)玄参(五 分, 去土)苦参(五分, 去皮)桔梗(五分, 去土)” 此处 “心悬, 饥不欲食” 是指胃脘胀闷, 如有物悬, 食后 尤甚。方中大黄当荡涤肠胃积滞, 痋虫与当归合用, 能过养血破瘀; 人参补脾胃中州之气; 干姜、附子 温肾健脾; 玄参、苦参合用, 燥湿而不伤阴; 葍本、防风、桔梗通肺气, 利肠胃。该方攻补兼施, 寒热 并用正中慢性萎缩性胃炎久病入络、本虚标实、寒热错杂之病机。10 多年来, 王道坤教授用敦煌平胃丸 治疗病人 1 万多例, 有效率达 $98 \%$, 彻底治愈率达 $62 \%$, 在临床中取得了很好的疗效[25]。

张士卿教授运用敦煌古医方神明白膏(以羊毛脂代替原方猪脂并配合凡士林)治疗老年性皮肤疼痒病 取得良好疗效。

敦煌医学卷子《杂证方书第九种》(P·3731)神明白膏: 主百病, 中风恶气及头面诸病, 青盲、风目烂

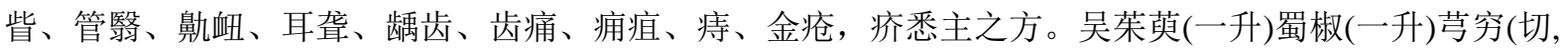
一升)白术(切, 一升)白芷(切, 一升)前胡(切, 一升)桂心(二两)当归(二两)细辛(二两)附子(三十枚, 生者) 酽米醋(五升)猪脂(一升、二升)上切, 以醋溲渍一宿, 以猪脂微火煎三下, 绞去漳, 有疾以摩敷之。若耳 目病内着之。

张士卿教授运用神明白膏进行治疗老年性皮肤瘙痒病临床与实验研究。治疗组(神明白膏) 100 例, 对 照组(999 皮炎平软膏)30 例, 均以外用药涂搽瘙痒部位, 疗程 1 个月。结果: 治疗组临床治愈率 $46 \%$, 总有效率 92\%; 对照组临床治愈率 17\%, 总有效率 67\%。治疗组有效率明显高于对照组。实验研究表明: 神明白亳具有抗炎、止痒作用, 对用药部位皮肤无刺激性、过敏反应, 局部用药未见毒副作用。因此, 敦煌古医方神明白膏使用是安全的。

神明白膏制方思想分析: 以吴荣英、桂心、附子等温里药为主, 温阳散寒, 健脾益肾; 蜀椒、白芷 辛香走踛, 祛在表之邪; 当归、川芎活血养血润燥。神明白膏区别于一般社风止痒方在于重在扶正而非 单纯祛风止痒。

现代医学认为老年性皮肤疼痒病的发生与老年人性腺、内分泌机能减退、皮脂腺、汗腺萎缩, 皮肤 干燥有关。老年人皮肤处于萎缩、退化阶段, 其保护功能减退, 对外界刺激, 特别是对干燥、寒冷因素 敏感而发病。故本病的治疗, 应重在扶正, 而非单纯社风止痒论治[26]。

敦煌医学卷子中载有许多膏摩医方, 以辛温药物为主组方, 主要通过皮肤作用于人体, 起到活血通 脉的作用[27]。

\section{3. 给药途径}

敦煌医学卷子载有舌下给药的方法。《辅行诀脏腑用药法要》记载: 硝石雄黄散研极细末, 舌下含 服。此与急救心绞痛、心梗舌下含服硝酸甘油不谋而合, 却比它早一千多年[1]。

\section{5. 讨论}

综上所述, 有大量的敦煌古医方应用于文献研究、实验研究、临床研究, 不仅说明敦煌古医方是敦 
煌医学的重要组成部分, 而且显示出学者前辈对于敦煌古医方的研究成果颇丰、社会认可度较高。然而, 在如此多的研究中, 对敦煌古医方药量的研究却风毛麟角, 中医方不传之秘在于药量, 可见药量对于方 剂的重要性。因此, 统计药量在敦煌古医方中的应用规律对于发掘敦煌古医方价值具有重要意义。

\section{6. 结论}

目前关于敦煌古医方方药剂量研究很少, 而中医方不传之秘在于药量, 因此敦煌古医方方药剂量值 得深入研究。

\section{参考文献 (References)}

[1] 丛春雨 (1994) 敦煌中医药全书. 中国古籍出版社, 北京, 6-51.

[2] 李应存 (2011) 敦煌佛教医方的研究价值探析. 中国庆阳 2011 岐黄文化暨中华中医药学会医史文献分会学术会, 庆阳.

[3] 刘喜平 (2004) 敦煌古医方的研究概况. 中成药, 26, 257.

[4] 刘喜平 (2004) 敦煌遗书中的中医方剂学成就. 中国中医基础医学杂志, 10, 75.

[5] 张辉, 张如青 (2006) 敦煌写本《张仲景五脏论》中有关药对及方剂探析. 上海中医药杂志, $\mathbf{4 0}, 36$.

[6] 梁永宣 (2008) 敦煌残卷 S.079 碎片与仲景关系考. 中医药文化, 3, 20-22.

[7] 李应存, 史正刚 (2007) 敦煌医学卷子《辅行诀脏腑用药法要》. 中医药通报, 6, 39.

[8] 张卫华, 杨殿兴 (2005) 《辅行决·汤液经图》诠释. 江西中医学院学报, 17, 18.

[9] 僧海霞 (2006) 敦煌文书中的药用酒研究. 南京中医药大学学报, 7, 96-99.

[10] 张靖 (2015) 敦煌遗书《黑帝要略方》探析. 西部中医药, 28, 43-44.

[11] 孙其斌，袁仁智 (2014) 敦煌汉简中的医药简探讨. 中国科技, 27, 42-43.

[12] 薛守宇, 梁丽娟, 安霞 (2011) 敦煌遗书之妇科方书残卷集萃. 中医研究, 24, 77-80.

[13] 从春雨 (2001) 论醋在敦煌遗书、马王堆竹简古医方中的临床应用. 敦煌研究, (2), 142-146.

[14] 李应存, 柳长华 (2013) 敦煌紫苏煎方源及相关医方探析. 西部中医药, 26, 26-28.

[15] 李希斌, 彭雪晶 (2014) 敦煌固本方对运动负荷小鼠股四头肌细胞内钻离子含量和相关酶活性的影响. 中医研 究, 27, 66-68.

[16] 杨雅丽, 耿广琴, 陈彻, 李希斌, 楚惠媛, 张莹 (2013) 敦煌固本方对运动性疲劳小鼠自由基代谢及 DNA 损伤的 影响. 中医药学报, 41, 58-61.

[17] 李希斌, 杨雅丽, 楚惠媛, 陈彻, 安方玉, 林海龙, 马晓燕 (2013) 敦煌固本方抗疲劳作用的实验研究. 时珍国 医国药, 23, 2803-2804.

[18] 赵健雄 (1988) 敦煌医粹. 贵州人民出版社, 贵阳, 12-30.

[19] 付航, 刘喜平, 张炜, 李沛清 (2015) 敦煌平胃丸对胃癌前病变大鼠 Notch 信号通路中 Notch2 和 Jagged1 表达的 影响．中国民族民间医药，(1), 18-20.

[20] 段永强, 王道坤, 成映霞, 等 (2007) 敦煌石室大宝胶囊对果蝇寿命影响的实验研究. 中成药, 29, 287-288.

[21] 程容, 段永强, 成映霞, 梁玉洁, 王道坤 (2010) 敦煌石室大宝胶囊对衰老大鼠脑组织单胺类神经递质的影响. 中国老年学杂志 30, 478-480.

[22] 程容, 段永强, 成映霞, 梁玉洁, 朱立鸣 (2010) 敦煌石室大宝胶囊对衰老大鼠脑组织钻稳态的影响. 中国老年 学杂志, 30, 3514-3516.

[23] 许辉, 孙守华 (2014) 敦煌古方治疗臌胀探析. 西部中医药, 27, 24-25.

[24] 李应存 (2005) 浅谈敦煌医学卷子中的诃梨勒组方. 中国医药通报, 4, 30-31.

[25] 李应存, 王道坤 (2007) 教授运用敦煌石窟秘方治疗慢性萎缩性胃炎选介. In: 第三届著名中医药学家学术传承 高层论坛，广州, 2007 年 11 月 26 日, 633. 
[26] 张士卿, 夏智波, 朱学艺, 等 (2003) 敦煌古方神明白膏治疗老年性皮肤瘙痒病临床与实验研究. 中医药学刊, 21, 86-88.

[27] 史正刚，刘喜平，张炜，段永强 (2015) 敦煌遗书膏摩古医方探析. 中国民族民间医药, 24, 4-5. 